\title{
Correction to: Novel Control of the Synthesis and Band Gap of Zinc Aluminate (ZnAl204) by Using a DC/RF Sputtering Technique
}

\author{
Asim Jilani ${ }^{1}$ - I. S. Yahia ${ }^{2,3}$ - M. Sh. Abdel-wahab ${ }^{1}$ - Attieh A. Al-ghamdi ${ }^{4}$ Haya Alhummiany ${ }^{5}$
}

Published online: 20 June 2018

(c) Springer Nature B.V. 2018

Erratum to: Silicon (2018) 10:1217-1223

https://doi.org/10.1007/s12633-017-9595-0

Due to an oversight, the Surname of Haya Alhummiany was incorrectly spelled in the published online version. The correct surname is "Alhummiany", instead of "Alhumminay". The correct spelling is also shown above.

The online version of the original article can be found at https://doi.org/10.1007/s12633-017-9595-0.

\footnotetext{
Asim Jilani

asim.jilane@gmail.com; asim.jilane@ hotmail.com

1 Center of Nanotechnology, King Abdulaziz University, Jeddah, Saudi Arabia

2 Nano-Science \& Semiconductor Labs, Metallurgical Laboratory, Department of Physics, Faculty of Education, Ain Shams University, Roxy, 11757 Cairo, Egypt

3 Advanced Functional Materials \& Optoelectronic Laboratory (AFMOL), Department of Physics, Faculty of Science, King Khalid University, P.O. Box 9004, Abha, Saudi Arabia

4 Department of Physics, Faculty of Science, University of Jeddah, Jeddah, Saudi Arabia

5 Department of Physics, Sciences Faculty for Girles, King Abdulaziz University, Jeddah, Saudi Arabia
} 